\title{
ACIDENTES PERFUROCORTANTES ENTRE TRABALHADORES DE ENFERMAGEM DE UM HOSPITAL UNIVERSITÁRIO DO INTERIOR PAULISTA ${ }^{1}$
}

\author{
Silvia Rita Marin da Silva Canini ${ }^{2}$ \\ Elucir $\mathrm{Gir}^{3}$ \\ Miyeko Hayashida ${ }^{4}$ \\ Alcyone Artioli Machado ${ }^{5}$
}

Canini SRMS, Gir E, Hayashida M, Machado AA. Acidentes perfurocortantes entre trabalhadores de enfermagem de um hospital universitário do inteiror paulista. Rev Latino-am Enfermagem 2002 março-abril; 10(2):172-8.

Como mostra a literatura, o risco de trabalhadores da área da saúde adquirirem patógenos veiculados pelo sangue já está bem documentado e demonstra que a Aids e a hepatite B e C, adquiridas de maneira ocupacional, são, hoje, um fato concreto. Este estudo retrospectivo, de natureza descritiva, realizado em um Hospital Universitário, no ano de 1998, objetivou analisar os acidentes perfurocortantes que acometeram os trabalhadores de enfermagem. Os resultados evidenciaram que, dos 398 acidentes ocupacionais notificados oficialmente, $125(30,40 \%)$ foram perfurocortantes e 89 (71,20\%) ocorreram entre trabalhadores de enfermagem. As situações mais freqüentes de ocorrência se deram quando da administração de medicamentos (25,78\%). Concluiu-se que os trabalhadores de enfermagem foram os mais atingidos pelos acidentes ocupacionais envolvendo material perfurocortante.

DESCRITORES: riscos ocupacionais, equipe de enfermagem

\section{NEEDLESTICK INJURIES AMONG NURSING STAFF MEMBERS AT A UNIVERSITY HOSPITAL IN THE INTERIOR OF SÃO PAULO STATE}

The risk presented by health care workers of acquiring bloodborne pathogens is well documented by the literature, which shows that Aids and Hepatitis acquired in the work setting is a real fact. This descriptive retrospective study was conducted in a university hospital in 1998 and aimed at analyzing needlestick injuries in nursing workers. Results showed that of the 398 officially reported occupational accidents, 125 (30.40\%) were needlestick injuries and that $89(71.20 \%)$ occurred among nursing workers. The most frequent occurrences took place during medication administration (25.78\%). Authors concluded that nursing workers were the most frequently victimized workers by occupational accidents involving needlestick injuries.

DESCRIPTORS: occupational risk, nursing team

\section{ACCIDENTES CORTO-PUNZANTES ENTRE TRABAJADORES DE ENFERMERÍA DE UN HOSPITAL UNIVERSITARIO DEL INTERIOR PAULISTA}

Como muestra la literatura, el riesgo de adquirir patógenos diseminados por la sangre en trabajadores de la área de salud, ya esta bien documentado y demuestra que el SIDA y la hepatitis $B$ y $C$ adquiridas de manera ocupacional son hoy en día un hecho concreto. Este estudio retrospectivo, de naturaleza descriptiva, realizado en un Hospital Universitario, en el año 1998; pretendió analizar los accidentes cortopunzantes que afectaron a los trabajadores de enfermería. Los resultados evidenciaron que, de los 398 accidentes ocupacionales notificados oficialmente, 125 (30,40\%) fueron corto-punzantes y 89 (71,20\%) ocurrieron entre trabajadores de enfermería. Las situaciones más frecuentes de ocurrencia se dieron con la administración de medicamentos (25,78\%). Se concluye que los trabajadores de enfermería fueron los más afectados por los accidentes ocupacionales con materiales corto-punzantes.

\section{DESCRIPTORES: riesgos ocupacionales, equipo de enfermería}

\footnotetext{
${ }^{1}$ Parte da Dissertação de Mestrado apresentada à Escola de Enfermagem de Ribeirão Preto-USP, 2000; ${ }^{2}$ Enfermeira, e-mail: canini@eerp.usp.br; ${ }^{3}$ Enfermeira, Professor Associado; ${ }^{4}$ Enfermeira do Trabalho, Doutor em Enfermagem. Escola de Enfermagem de Ribeirão Preto da Universidade de São Paulo, Centro Colaborador da OMS para o desenvolvimento da pesquisa em enfermagem; ${ }^{5}$ Médica, Professor Doutor da Faculdade de Medicina de Ribeirão Preto da Universidade de São Paulo
} 
INTRODUÇÃO

$\boldsymbol{P}_{\text {or ser uma atividade eminentemente social, o trabalho }}$ exerce um papel fundamental nas condições de vida do homem. Produz efeito positivo, quando é capaz de satisfazer as necessidades básicas de subsistência, de criação e de colaboração dos trabalhadores. Por outro lado, ao realizá-lo, o homem expõe-se constantemente aos riscos presentes no ambiente laboral, os quais podem interferir diretamente em sua condição de saúde ${ }^{(1)}$.

0 ambiente hospitalar oferece múltiplos e variados riscos aos trabalhadores da área da saúde, tais como os causados por agentes químicos, físicos, biológicos, psicossociais e ergonômicos ${ }^{(2)}$, sendo os riscos biológicos os principais geradores de periculosidade e insalubridade a esses trabalhadores ${ }^{(3)}$.

A transmissão ocupacional do Vírus da Imunodeficiência Humana (HIV) tornou-se um grande desafio aos profissionais de Controle de Infecção Hospitalar e Saúde Ocupacional, após uma enfermeira ter desenvolvido Aids, em conseqüência de picada acidental com uma agulha que continha sangue de um paciente infectado pelo HIV, internado em um hospital da Inglaterra ${ }^{(4)}$.

Preocupados com a transmissão desses patógenos, os Centers for Disease Control and Prevention (CDC) publicaram as recomendações para prevenção da transmissão do HIV e de outros patógenos veiculados pelo sangue em estabelecimentos de assistência à saúde ${ }^{(5)}$, e recomendaram a utilização das precauções universais, atualmente denominadas precauções-padrão, como medida de prevenção para esse tipo de exposição( ${ }^{(6)}$.

Dentre os fluidos corporais, tem-se reconhecido o sangue como o mais importante veículo de transmissão ocupacional dos vírus da hepatite $\mathrm{C}(\mathrm{HCV})$, da hepatite $\mathrm{B}(\mathrm{HBV})$ e o $\mathrm{HIV}^{(7)}$.

Os fatores de risco para aquisição do HCV após exposição ocupacional, dependem do grau de contato com o sangue ou com instrumentos cortantes e da prevalência de anti-HCV entre os pacientes $^{(10)}$, podendo variar de 1 a $10 \%{ }^{(8)}$.

Em relação ao HBV, o risco pode variar de 6 a $30 \%$, podendo atingir até $40 \%$ em exposição relacionada com paciente-fonte que apresenta $\mathrm{o}$ antígeno de superfície $\mathrm{HbsAg}$ presente e quando nenhuma medida profilática é adotada ${ }^{(9)}$.

Estudos prospectivos estimam que o risco de transmissão do HIV, após acidente com perfurocortantes e paciente-fonte sabidamente positivo, é de 0,3 a 0,5\% e, após exposição de membrana mucosa, é de $0,09 \%$. A transmissão relacionada à exposição de pele tem sido documentada, porém seu risco ainda não foi quantificado ${ }^{(10)}$.

No Brasil, a escassez de dados sistematizados sobre acidentes ocupacionais envolvendo material biológico e, mais especificamente, material perfurocortante, não nos permite conhecer a magnitude desse problema, dificultando, assim, a implementação e a avaliação das medidas preventivas.

A vivência profissional, em um hospital universitário do interior paulista, no âmbito assistencial e como integrante da Comissão de Controle de Infecção Hospitalar $(\mathrm{CCIH})$, permitiu 0 contato freqüente com trabalhadores da área da saúde, principalmente da enfermagem, que se acidentam com materiais perfurocortantes, motivando a realização dessa pesquisa.

\section{OBJETIVOS}

- Identificar a freqüência dos acidentes ocorridos com materiais perfurocortantes, em relação ao número total de acidentes ocupacionais, notificados legalmente ao Serviço Especializado em Engenharia de Segurança e Medicina do Trabalho (SESMT).

- Identificar a freqüência dos acidentes ocupacionais com materiais perfurocortantes, notificados legalmente ao SESMT, ocorridos entre trabalhadores da equipe de enfermagem.

- Identificar a distribuição dos acidentes com materiais perfurocortantes entre os trabalhadores da equipe de enfermagem, segundo notificação ao SESMT e/ou atendimento no Ambulatório de Atendimento de Acidentes Ocupacionais aos Profissionais de Saúde (AOPS).

- Identificar as situações de ocorrência dos acidentes com materiais perfurocortantes, ocorridos entre trabalhadores da equipe de enfermagem.

\section{MÉTODOS}

Para o desenvolvimento desta pesquisa sobre os acidentes ocupacionais com materiais perfurocortantes entre trabalhadores de enfermagem, realizou-se um estudo descritivo de caráter retrospectivo, com análise dos acidentes ocupacionais dessa natureza, notificados ao SESMT e/ou atendidos no AOPS, ocorridos no Hospital das Clínicas da Faculdade de Medicina de Ribeirão Preto da Universidade de São Paulo (HCFMRP-USP), no período de $1^{\circ} \mathrm{de}$ janeiro a 31 de dezembro de 1998.

A população do estudo foi composta por trabalhadores do HCFMRP-USP que notificaram acidentes de trabalho ao SESMT, no ano de 1998, num total de 398 acidentes; e a amostra, por trabalhadores de enfermagem que registraram 127 acidentes com materiais perfurocortantes, no mesmo ano, sendo 89 notificados no SESMT e, 38 registrados no AOPS.

Nesse hospital, existe o AOPS, criado em janeiro de 1997, onde se realiza 0 atendimento dos trabalhadores expostos a materiais 
biológicos, com o intuito de normatizar a dispensação de medicações e, também, o seguimento dos trabalhadores vítimas desses acidentes, porém esse registro não tem efeito legal. A notificação legal do acidente deve ser feita ao SESMT para posterior emissão da Comunicação de Acidente de Trabalho (CAT), pelo Centro de Recursos Humanos.

Portanto, o procedimento correto no caso de acidentes envolvendo materiais biológicos é procurar atendimento no AOPS e notificar 0 acidente ao SESMT, pois, nesse hospital, os dois atendimentos são complementares.

A primeira etapa da coleta de dados foi realizada no SESMT, com o objetivo de identificar a freqüência dos acidentes de trabalho ocorridos no HCFMRP-USP, no ano de 1998; posteriormente, foram coletados os dados referentes aos atendimentos realizados no AOPS, nesse mesmo período. Os dados foram processados e analisados pelo programa EPI-INFO 6.0.

O projeto de pesquisa foi aprovado pelo Comitê de Ética em Pesquisa, do referido hospital.

\section{RESULTADOS E DISCUSSÃO}

Ao se analisar o conjunto de acidentes ocupacionais (Tabela 1), apurou-se que, dos 398 acidentes notificados ao SESMT em 1998, $125(31,40 \%)$ foram acidentes perfurocortantes, e 273 (68,60\%) corresponderam a outros acidentes ocupacionais, como exposição cutâneo-mucosa, quedas, entorses, acidentes de trajeto, fraturas, queimaduras, entre outros.

Tabela 1 - Distribuição dos acidentes ocupacionais notificados ao SESMT de um hospital universitário, segundo o tipo de acidente e mês de ocorrência, no ano de 1998

\begin{tabular}{|c|c|c|c|c|c|c|}
\hline \multirow[t]{2}{*}{ Hês } & \multicolumn{2}{|c|}{$\begin{array}{l}\text { Acidentes ocupacionais com } \\
\text { materiais perfurocortentes }\end{array}$} & \multicolumn{2}{|c|}{ Outros acidentes ocupacionais } & \multicolumn{2}{|c|}{ Total } \\
\hline & $n^{0}$ & $\%$ & $n^{0}$ & $\%$ & $n^{0}$ & $\%$ \\
\hline Janeiro & 08 & 28,57 & 20 & 71,43 & 28 & 100,0 \\
\hline Fevereiro & 10 & 33,33 & 20 & 66,67 & 30 & 100,0 \\
\hline Março & 09 & 25,71 & 26 & 74,29 & 35 & 100,0 \\
\hline Abril & 11 & 34,38 & 21 & 65,62 & 32 & 100,0 \\
\hline Maio & 11 & 31,31 & 24 & 68,57 & 35 & 100,0 \\
\hline Junho & 10 & 29,41 & 24 & 70,59 & 34 & 100,0 \\
\hline Julho & 12 & 31,58 & 26 & 68,42 & 38 & 100,0 \\
\hline Agosto & 16 & 37,21 & 27 & 62,79 & 43 & 100,0 \\
\hline Setembro & 15 & 46,87 & 17 & 53,13 & 32 & 100,0 \\
\hline Outubro & 09 & 30,00 & 21 & 70,00 & 30 & 100,0 \\
\hline Novembro & 12 & 36,36 & 21 & 63,64 & 33 & 100,0 \\
\hline Dezembro & 02 & 7,14 & 26 & 92,86 & 28 & 100,0 \\
\hline Total & 125 & 31,40 & 273 & 68,60 & 398 & 100,0 \\
\hline
\end{tabular}

0 percentual de acidentes ocupacionais com materiais perfurocortantes, ao longo dos meses (Tabela 1), manteve-se próximo de um terço dos acidentes ocorridos (com variação entre $25,71 \%$ e $37,21 \%)$, exceto nos meses de dezembro $(7,14 \%)$ e setembro $(46,87 \%)$.

Achados semelhantes foram descritos na literatura, apontando índice de acidentes perfurocortantes de $30,71 \%{ }^{(11)}$.
Ao se analisarem as notificações mensais dos acidentes ocupacionais com materiais perfurocortantes (Tabela 2), pôde-se observar que ocorreram predominantemente entre trabalhadores de enfermagem, variando entre 66,67 a 100\%, com exceção do mês de janeiro, quando a distribuição também foi igual nas outras categorias funcionais. 
Tabela 2 - Distribuição dos acidentes ocupacionais com materiais perfurocortantes notificados ao SESMT de um hospital universitário, segundo as categorias funcionais e mês de ocorrência, no ano de 1998

\begin{tabular}{|c|c|c|c|c|c|c|}
\hline \multirow[t]{2}{*}{ Hês } & \multicolumn{2}{|c|}{ Trabalhadores de Enfermagem } & \multicolumn{2}{|c|}{ Outras categorias funcionais } & \multicolumn{2}{|c|}{ Total } \\
\hline & $n^{0}$ & $\%$ & $n^{0}$ & $\%$ & $n^{0}$ & $\%$ \\
\hline Janeiro & 04 & 50,00 & 04 & 50,00 & 08 & 100,0 \\
\hline Fevereiro & 07 & 70,00 & 03 & 30,00 & 10 & 100,0 \\
\hline Março & 06 & 66,67 & 03 & 33,33 & 09 & 100,0 \\
\hline Abril & 08 & 72,73 & 03 & 27,27 & 11 & 100,0 \\
\hline Maio & 09 & 81,82 & 02 & 18,18 & 11 & 100,0 \\
\hline Junho & 07 & 70,00 & 03 & 30,00 & 10 & 100,0 \\
\hline Julho & 08 & 66,67 & 04 & 33,33 & 12 & 100,0 \\
\hline Agosto & 11 & 68,75 & 05 & 31,25 & 16 & 100,0 \\
\hline Setembro & 11 & 73,33 & 04 & 26,67 & 15 & 100,0 \\
\hline Outukbo & 08 & 80,89 & 01 & 11,11 & 09 & 100,0 \\
\hline Novembro & 08 & 66,67 & 04 & 33,33 & 12 & 100,0 \\
\hline Dezembro & 02 & 100,00 & 0 & 0 & 02 & 100,0 \\
\hline Total & 89 & 71,20 & 36 & 28,00 & 125 & 100,0 \\
\hline
\end{tabular}

Os trabalhadores de enfermagem estão distribuídos nas seguintes categorias: enfermeiros, técnicos de enfermagem, auxiliares de enfermagem e atendentes de enfermagem. As outras categorias funcionais incluem pessoal da limpeza, manutenção, lavanderia, técnicos de laboratório, entre outros.

Em relação à distribuição dos 125 acidentes perfurocortantes notificados ao SESMT, conforme Tabela 1, constatou-se que $89(71,20 \%)$ foram notificados por elementos da equipe de enfermagem, e $36(28,80 \%)$, por trabalhadores de outras categorias funcionais. Dos 36 acidentes ocorridos com trabalhadores de outras categorias funcionais (Tabela 3), a maioria acometeu os trabalhadores do Serviço de Higiene e Limpeza $(47,22 \%)$.

Tabela 3 - Distribuição dos acidentes ocupacionais com materiais perfurocortantes notificados ao SESMT de um hospital universitário, ocorridos entre as outras categorias funcionais, no ano de 1998

\begin{tabular}{lcc}
\hline \multicolumn{1}{c}{ Categoria funcional } & \multicolumn{2}{c}{$\begin{array}{c}\text { Acidentes com materiais } \\
\text { perfurocortentes }\end{array}$} \\
\hline & $\mathbf{n}^{\mathbf{0}}$ & $\%$ \\
\hline Auxiliar do Serviço de Higiene e Limpeza & 17 & 47,22 \\
Auxiliar do Serviço de Lavanderia & 07 & 19,44 \\
Auxiliar do Serviço de Manutençẫo & 05 & 13,89 \\
Técrico de Laboratório & 05 & 13,89 \\
Outras & 02 & 5,56 \\
\hline Total & $\mathbf{3 6}$ & $\mathbf{1 0 0 , 0}$ \\
\hline
\end{tabular}

Os trabalhadores de enfermagem são os que mais manipulam esses materiais; logo acabam sendo os maiores responsáveis por seu descarte inadequado e, conseqüentemente, pela maior exposição dos trabalhadores de outras categorias funcionais a esse risco.
Um estudo analisando 710 acidentes percutâneos e exposição cutâneo-mucosa em um hospital universitário da cidade de São Paulo, encontrou que 38,5\% deles atingiram os técnicos e auxiliares de enfermagem, seguidos por $20 \%$ dos funcionários da limpeza ${ }^{(12)}$.

Em relação à distribuição desses acidentes entre as outras categorias funcionais, os dados obtidos por meio das fichas de notificação do SESMT revelam que a maioria deles são ocasionados por agulhas e outros objetos perfurocortantes, descartados em locais impróprios: no leito do paciente, na mesa de cabeceira, na bandeja de medicação, no chão e no lixo comum. Esses dados evidenciam, ainda, que, entre os trabalhadores da área de apoio hospitalar, os do setor de limpeza são os que mais sofrem com os acidentes perfurocortantes. Medidas preventivas, como adequação das caixas de descarte de materiais perfurocortantes, treinamento específico que oriente os trabalhadores da área da saúde sobre os riscos biológicos e a importância da vacinação contra hepatite $B$, podem contribuir para a diminuição dessas ocorrências entre tais trabalhadores.

Assim, medidas preventivas de acidentes perfurocortantes devem ser estendidas a todos os trabalhadores da área da saúde. A conscientização dos elementos da equipe de enfermagem, quanto à necessidade de descartar os materiais perfurocortantes em local adequado, pode influenciar diretamente a redução desse tipo de acidente, não só entre eles, mas também entre os demais trabalhadores da área da saúde.

Até o momento, foram apresentados os resultados obtidos por meio das notificações de acidentes com materiais perfurocortantes feitas apenas ao SESMT (Tabelas 1, 2 e 3), que totalizaram 125 acidentes dessa natureza, entre todas as categorias de trabalhadores, 
sendo 89 , com a equipe de enfermagem, $\mathrm{e} 36$, com outras categorias de trabalhadores.

Nas tabelas subseqüentes, serão considerados os acidentes notificados ao SESMT e registrados no AOPS, ocorridos somente entre os trabalhadores de enfermagem, totalizando 127 acidentes.

Os dados contidos na Tabela 4 revelam que, dos 127 acidentes com perfurocortantes registrados ou notificados por trabalhadores de enfermagem, 71 (55,91\%) foram legalmente notificados ao SESMT, por meio da CAT emitida pelo Centro de Recursos Humanos, e concomitantemente atendidos no AOPS.

Tabela 4 - Distribuição dos acidentes ocupacionais com materiais perfurocortantes ocorridos com trabalhadores de enfermagem de um hospital universitário, segundo o local de registro, no ano de 1998

\begin{tabular}{llc}
\hline Local de registro & \multicolumn{2}{c}{$\begin{array}{c}\text { Acidentes com materiais } \\
\text { perfurocortantes }\end{array}$} \\
\hline & $\mathbf{n}^{\mathbf{0}}$ & $\%$ \\
\hline SESMTIAOPS & 71 & 55,91 \\
SESMT & 18 & 14,17 \\
AOPS & 38 & 29,92 \\
\hline Total & $\mathbf{1 2 7}$ & $\mathbf{1 0 0 , 0}$ \\
\hline
\end{tabular}

Os dois atendimentos são complementares e configuram o procedimento correto para esse tipo de acidente. Os 18 acidentes $(14,17 \%)$ notificados apenas no SESMT deixaram de receber parte importante do atendimento que é realizado no AOPS. Considerando que 38 acidentes não foram notificados ao SESMT, o índice de subnotificação de acidentes perfurocortantes, neste estudo, foi de $29,92 \%$; julga-se, porém, que, se esse dado fosse obtido mediante entrevista de todos os trabalhadores de enfermagem, o índice poderia ser maior, ou seja, talvez fossem encontrados trabalhadores que se acidentaram e não registraram o fato em nenhum dos dois locais. Dada a relevância do problema, estudos futuros com foco nessa temática poderão contribuir para melhor retratar a realidade desses acidentes na instituição.

A subnotificação de acidentes tem sido alvo de estudos de outros pesquisadores, e um deles revelou um índice de $91,9 \%$ de subnotificação entre trabalhadores de enfermagem, sendo os acidentes perfurocortantes os de maior índice de subnotificação $(34,4 \%)$. Nesse mesmo estudo, a principal causa de subnotificação atribuída pelos sujeitos foi considerar pequena a lesão, sem importância (53,1\%), seguida do desconhecimento referente ao dever de comunicar o acidente $(36,8 \%)^{(13)}$. Em outro estudo, encontrou-se um índice de subnotificação de acidentes perfurocortantes de $51 \%$, e a subnotificação de acidentes relacionados à prática de reencapar agulhas foi, aproximadamente, de $85 \%{ }^{(14)}$.
Ainda em relação à subnotificação de acidentes, uma pesquisa detectou que $98,6 \%$ dos profissionais da área da saúde de um hospital da Tailândia, que foram entrevistados, não notificaram suas injúrias mais recentes, devido a três determinantes principais: a) os dispositivos não haviam sido utilizados em pacientes (34\%); b) estavam muito ocupados na ocasião do acidente $(14,9 \%)$; c) desconheciam o mecanismo de notificação dos acidentes $(14,4 \%)^{(15)}$.

Os dados levantados no SESMT e no AOPS mostram a diversidade de conduta para esses acidentes, em face do atendimento e do tipo de notificação, tornando-se necessário, num primeiro momento, o esclarecimento a todos os trabalhadores da instituição sobre o procedimento correto na ocorrência de acidentes perfurocortantes, uma vez que apenas $55,91 \%$ desses acidentes tiveram o procedimento correto.

Quando analisamos a simples distribuição do número de acidentes perfurocortantes entre as categorias funcionais de enfermagem (Tabela 5), podemos ver que o maior número de acidentes ocorreu entre os auxiliares de enfermagem (62,99\%), seguido pelos enfermeiros $(21,26 \%)$, técnicos de enfermagem $(11,81 \%)$ e atendentes de enfermagem $(3,94 \%)$.

Tabela 5 - Distribuição dos acidentes ocupacionais com materiais perfurocortantes ocorridos com trabalhadores de enfermagem de um hospital universitário, notificados ao SESMT e/ou atendidos no AOPS, segundo a categoria funcional, no ano de 1998

\begin{tabular}{lcc}
\hline Categoria funcional & \multicolumn{2}{c}{$\begin{array}{c}\text { Acidentes com materiais } \\
\text { perfurocortantes }\end{array}$} \\
\hline & $\mathbf{n}^{\mathbf{0}}$ & $\%$ \\
\hline Enfermeiro & 27 & 21,26 \\
Técnico de Enfermagem & 15 & 11,81 \\
Auxiliar de Enfermagem & 80 & 62,99 \\
Atendente de Enfermagem & 05 & 3,94 \\
\hline Total & $\mathbf{1 2 7}$ & $\mathbf{1 0 0 , 0}$ \\
\hline
\end{tabular}

Os auxiliares de enfermagem são o maior contingente entre as categorias de enfermagem e os que mais estão em contato direto com o paciente, portanto sofrendo maior exposição a esse tipo de risco.

O número de atendentes de enfermagem tem diminuído gradativamente na instituição. Segundo dados referentes ao ano de 1998, fornecidos pela Divisão de Enfermagem do HCFMRP-USP, em janeiro representavam $7,40 \%$ dos trabalhadores de enfermagem e, em dezembro, 4,59\%.

De acordo com estatísticas nacionais do Conselho Federal de Enfermagem, até abril de 1997, a distribuição dos trabalhadores de enfermagem era a seguinte: enfermeiros $(12,8 \%)$, técnicos de enfermagem (11,3\%), auxiliares de enfermagem $(49,6 \%)$ e atendentes em enfermagem, $(26,2 \%)^{(16)}$. 
Quando se analisam as diferentes categorias funcionais da enfermagem, vale a pena ressaltar que 0 fato de essa equipe ter membros com formação bastante heterogênea requer programas de educação em serviço, elaborados de maneira a contemplar essas diferenças.

Os acidentes perfurocortantes representam uma parcela importante do total de acidentes ocupacionais notificados no HCFMRP-USP, podemos observar na Tabela 6 que parte deles poderia ter sido evitada pela aplicação das precauções padrão, que incluem a manipulação cuidadosa de objetos perfurocortantes, a não reencapagem de agulhas e seu descarte em local apropriado.

Tabela 6 - Distribuição dos acidentes com materiais perfurocortantes ocorridos entre trabalhadores de enfermagem de um hospital universitário, segundo a situação de ocorrência, no ano de 1998

\begin{tabular}{|c|c|c|}
\hline \multirow[t]{2}{*}{ Situaģão de Ocorrência } & \multicolumn{2}{|c|}{$\begin{array}{l}\text { Acidentes com materiais } \\
\text { perfuroc ortentes }\end{array}$} \\
\hline & $n^{0}$ & $\%$ \\
\hline Administrando medicaçẫo & 30 & 23,62 \\
\hline Administrando soroterapia & 30 & 23,62 \\
\hline $\begin{array}{l}\text { Adingido por material descartado em local } \\
\text { impróprio }\end{array}$ & 10 & 7,80 \\
\hline Descartando materiais perfurocortantes & 10 & 7,80 \\
\hline Atingido por outro trabalhador & 08 & 6,30 \\
\hline Reencapando agulhas & 07 & 5,51 \\
\hline Manuseando aparelho de barbear & 06 & 4,72 \\
\hline Manuseando vidros e metais & 05 & 3,94 \\
\hline Colhendo sangue & 04 & 3,15 \\
\hline Limpando material & 03 & 2,36 \\
\hline Outros & 14 & 11,02 \\
\hline Total & 127 & 100,0 \\
\hline
\end{tabular}

De acordo com a situação de ocorrência dos acidentes perfurocortantes, pudemos observar que a maioria dos acidentes ocorreu quando os trabalhadores de enfermagem estavam administrando medicamentos $(23,82 \%)$, seguindo-se pela administração de soroterapia $(23,62 \%)$, por materiais descartados em local impróprio $(7,88 \%)$, pelo descarte de materiais perfurocortantes $(7,88 \%)$, por ser atingido por outro trabalhador $(6,30 \%)$ e ao se reencaparem agulhas $(5,51 \%)$.

Grande parte das atividades dos trabalhadores de enfermagem está concentrada na administração de medicamentos e soroterapia, atividades que envolvem a manipulação constante de agulhas e escalpes, sendo situações que mais expõem os trabalhadores ao risco de acidentes perfurocortantes.

Em relação ao descarte de material perfurocortante em local impróprio, índice semelhante foi encontrado na literatura, 5,1\%, e, no mesmo estudo, $65,7 \%$ dos acidentes que ocorreram nessa situação envolveram o pessoal da limpeza quando recolhiam o lixo comum ${ }^{(14)}$.
Ressaltamos que esse tipo de procedimento acomete não só os trabalhadores de enfermagem, mas é considerado a causa principal de acidentes entre as outras categorias de trabalhadores, principalmente do serviço de limpeza, lavanderia e manutenção

Dados divergentes foram relatados em outro estudo, quando 0 descarte de perfurocortantes em local impróprio foi 0 procedimento que mais ocasionou acidentes $(26,5 \%)$, seguido pela categoria medicando/puncionando $(19,3 \%)^{(17)}$.

Uma pesquisa analisando o conteúdo das caixas destinadas ao descarte de materiais perfurocortantes, na mesma instituição deste estudo, revelou que, das 1066 agulhas contidas em dez caixas, 681 $(63,9 \%)$ estavam reencapadas, $627(74,2 \%)$ estavam desconectadas das seringas, mostrando que, apesar de as precauções-padrão não recomendarem essa prática, ela ainda ocorre neste hospital ${ }^{(18)}$.

Frente a esses resultados, torna-se evidente a necessidade de se realizar um treinamento, principalmente do pessoal de enfermagem, em relação aos riscos de acidentes ocupacionais com materiais perfurocortantes, além de buscar alternativas que possam conferir maior segurança aos procedimentos realizados por esses trabalhadores.

\section{CONCLUSÕES}

Os acidentes ocupacionais com materiais perfurocortantes representaram $31,40 \%$ de todos os acidentes ocupacionais notificados ao SESMT, no ano de 1998.

A maioria dos acidentes perfurocortantes notificados ao SESMT $(71,20 \%)$ ocorreu entre trabalhadores de enfermagem.

Em relação ao total de acidentes registrados, $55,91 \%$ foram notificados por meio da CAT ao SESMT e atendidos no AOPS, representando o procedimento correto para esse tipo de acidentes na instituição; porém $44,09 \%$ dos acidentes foram considerados como procedimento incorreto, sendo que $14,17 \%$ foram notificados apenas ao SESMT, e $29,92 \%$ dos acidentados procuraram somente 0 atendimento no AOPS.

Os auxiliares de enfermagem foram os mais atingidos por esse tipo de acidentes e, em relação à situação de ocorrência, as mais freqüentes foram: administrando medicamentos $(23,62 \%)$, administrando soroterapia $(23,62 \%)$; se somarmos as categorias reencapando agulhas $(5,51 \%)$, descartando materiais perfurocortantes $(7,88 \%)$ e descarte em local impróprio $(7,88 \%)$, teremos um total de $21,27 \%$ de acidentes ocasionados por situações que contrariam as precauções-padrão, portanto passíveis de prevenção. 
REFERÊNCIAS BIBLIOGRÁFICAS

1. Bulhões I. Riscos do trabalho de enfermagem. Rio de Janeiro (RJ): Folha Carioca; 1994.

2. Marziale MHP. Condições ergonômicas da situação de trabalho, do pessoal de enfermagem em uma unidade de internação hospitalar. [dissertação]. São Paulo (SP): Escola de Enfermagem de Ribeirão Preto/USP; 1995.

3. Suazo SVV. Contribuição ao estudo sobre acidentes de trabalho que acometem as trabalhadoras de enfermagem em hospitais chilenos. [dissertação]. São Paulo (SP): Escola de Enfermagem de Ribeirão Preto/USP; 1999.

4. Needlesticks transmission of HTLV-III from a patient infected in Africa. Lancet 1984; 8416(2):1376-7.

5. Centers for Disease Control and Prevention. Recomendations for prevention of HIV transmission in health-care settings. MMWR 1987; 25(36):3-18.

6. Garner JS. Guideline for isolation precautions in hospitals. Infect Control Hosp Epidemiol 1996; 1(17):54-80.

7. Pedrosa TMG, Couto RC. Prevenção das infecções nosocomiais ocupacionais. In: Couto RC, Pedrosa TMG, Nogueira JM Infecção hospitalar: epidemiologia, controle, gestão para a qualidade. Rio de Janeiro (RJ): Medsi; 1999. p. 585-611.

8. Shapiro $\mathrm{CN}$. Occupational risk of infection with hepatitis $B$ and hepatitis C virus. Surg Clin North Am 1995; 6(75):1047-56.

9. Ministério da Saúde (BR). Secretaria de Políticas de Saúde, Coordenação Nacional de DST e AIDS. Manual de condutas: exposição ocupacional a material biológico: hepatite e HIV. Brasília; 1999.

10. Centers for Disease Control and Prevention. Public health service guidelines for the management of health-care worker exposures to HIV and recommendation for post exposure prophylaxis. MMWR 1998; 47(RR-7): 1-33.
11. Benatti MCC. Acidente do trabalho em um Hospital Universitário: um estudo sobre a ocorrência e os fatores de risco entre trabalhadores de enfermagem. [dissertação]. São Paulo (SP): Escola de Enfermagem /USP; 1997.

12. Halker E, Parreira F, Costa ML, Ferrari ACS, Febré N, Wey SB, et al. Programa de notificação de acidentes percutâneos e exposição de mucosa para profissionais da área de saúde de um Hospital de ensino. In: Associação Brasileira dos Profissionais em Controle de Infecções e Epidemiologia Hospitalar. $5^{\circ}$ Congresso Brasileiro de Controle de Infecção e Epidemiologia Hospitalar; 1996. Rio de Janeiro (RJ); 1996. p. 127.

13. Napoleão AM. Causas de subnotificação de acidentes de trabalho: visão dos trabalhadores de um hospital do interior paulista. [dissertação]. São Paulo (SP): Escola de Enfermagem de Ribeirão Preto/USP; 1999.

14. Brevidelli MM. Exposição ocupacional aos vírus da AIDS e da hepatite B: análise da influência das crenças em saúde sobre a prática de reencapar agulhas. [dissertação]. São Paulo (SP): Escola de Enfermagem /USP; 1997.

15. Shiao JSC, McLaws ML, Huang KY, Ko WC, Guo YL. Prevalence of nonreporting behavior of sharps injuries in Taiwanese health care workers. AJIC 1999; 3(27):254-7.

16. Jansen AC. Um novo olhar para os acidentes de trabalho na enfermagem: a questão do ensino. [dissertação]. São Paulo (SP): Escola de Enfermagem de Ribeirão Preto/USP; 1999.

17. Souza M. Acidentes ocupacionais e situações de risco para equipe de enfermagem: um estudo em cinco hospitais do Município de São Paulo. [dissertação]. São Paulo (SP): Escola de Enfermagem de Ribeirão Preto/USP;1999.

18. Canini SRMS, Silva MHA, Gir E, Souza ACS, Machado AA. How have the needles being discharged in a Brazilian Hospital? Infect Control Hosp Epidemiol 2000;2(21):107. 